Elsevier

HRR 00899

\title{
Velocity of red blood cell flow in capillaries of the guinea pig cochlea
}

\author{
Alfred L. Nuttall \\ Kresge Hearing Research Institute, Dept. of Otolaryngology - Head and Neck Surgery, Medical School, The University of Michigan, \\ Ann Arbor, U.S.A.
}

(Received 12 November 1986; accepted 26 December 1986)

\begin{abstract}
Velocities of red blood cells (RBCs) in the lateral wall of the cochlea were determined in the anesthetized guinea pig from direct optical microscopic observations. Mean flow velocity of the blood was measured by timing the passage of a fluorescently-labeled subpopulation of RBCs across a measured capillary length. The optical observations were achieved using an intravital microscope equipped for epifluorescence and the measurements were derived from video images acquired with an image intensified television camera. In the third turn of the cochlea the velocity of RBCs differed significantly between two major classes of capillaries. The mean velocity in spiral ligament vessels was $0.12 \mathrm{~mm} / \mathrm{s}$ while stria vascularis flow was slower $(0.08 \mathrm{~mm} / \mathrm{s})$. In a typical animal, the range of velocities among different vessels of the ligament was $0.09-0.18 \mathrm{~mm} / \mathrm{s}$ while it was $0.03-0.10 \mathrm{~mm} / \mathrm{s}$ for stria vascularis vessels. Corresponding to this velocity difference, the apparent mean vessel diameters for the two types of vessels also differed. Spiral ligament capillaries were $9.3 \mu \mathrm{m}$ while strial capillaries were $12.2 \mu \mathrm{m}$ in diameter. Comparison of flow velocity in different turns of the cochlea indicated that the distribution of blood velocity throughout the cochlea lateral wall is constant.
\end{abstract}

Velocity, Red blood cell, Cochlea, Intravital microscopy, Fluorescence, Stria vascularis

\section{Introduction}

Capillary areas in the cochlea are complex and hypothetically serve differing functions. For example, the vessels of the lateral wall divide into four or five anatomically distinct capillary areas (Smith, 1951, 1954; Axelsson, 1968). Vessels entering the stria vascularis obviously have a different role, relating to the resulting function of the stria, from those passing through the spiral ligament. The relationship between circulation and function in a local tissue area of the cochlea can perhaps best be studied by direct microscopic observations of these systems. The current investigation begins such studies by determining the flow velocities of erythrocytes in the capillaries of the lateral wall in the normal guinea pig.

Correspondence to: A.L. Nuttall, Kresge Hearing Research Institute, 1301 East Ann Street, The University of Michigan Medical School, Ann Arbor, MI 48109, U.S.A.
Velocity of red blood cells (RBCs) in capillaries is one of the most important parameters of the microcirculation. It directly relates to the volume flow of blood and thus characterizes the degree of local tissue perfusion. It is proportional to the transit time across a capillary bed which in turn governs the time available for the exchange of respiratory gases. Thus, measurement of the normal velocities is essential to future studies which may examine pathological conditions or attempt to determine the mechanisms of flow control in the cochlea.

Weille et al. (1954) and Seymour (1954) were the first to make visual observations of the blood flow in the living cochlea. The mostly qualitative impressions they reported were soon supplemented by quantitative determinations of blood cell velocity by Perlman and Kimura (1955). Using frame-by-frame analysis of motion pictures taken through a microscope, Perlman and Kimura (1955, 1962) found that flow velocity of cells (mostly white blood cells) was low, ranging from below 0.1 $\mathrm{mm} / \mathrm{s}$ to about $0.3-0.4 \mathrm{~mm} / \mathrm{s}$. Nomura (1961) 
also characterized the capillary circulation as slow flow.

In contrast to the early results, a study by Costa and Branemark (1970a) observed flow velocities typically above $0.3 \mathrm{~mm} / \mathrm{s}$. Indeed the flow was categorized as fast in both the lateral wall and in other capillary areas.

The current study re-examines the question of the velocity of red blood cells in the vessels of the lateral wall and supports the general findings of Perlman and Kimura $(1955,1962)$. Flow velocities in capillaries of the spiral ligament averaged 0.12 $\mathrm{mm} / \mathrm{s}$ while the stria vascularis had a significantly slower flow rate of $0.08 \mathrm{~mm} / \mathrm{s}$. The current study extends the earlier findings by determining the comparative flow velocities in different cochlear turns. The data indicate that flow velocity is distributed evenly among the turns although variation in the size of the measured vessels is found.

\section{Materials and Methods}

Guinea pigs used in this study had body weights between 300 and $450 \mathrm{~g}$. They were anesthetized with diazepam ( $5 \mathrm{mg} / \mathrm{kg}$ body wt i.p.) and fentanyl $(0.32 \mathrm{mg} / \mathrm{kg}$ body wt i.m.). Supplemental doses of diazepam (at $1 / 2$ the initial amount) were given at $2 \mathrm{~h}$ intervals and of fentanyl (at $1 / 2$ the initial amount) at $1 / 2 \mathrm{~h}$ intervals. The animals were immediately wrapped in a thermostatically controlled heating pad which maintained rectally measured temperature at $38.5^{\circ} \mathrm{C}$. Heart rate was continuously monitored. A tracheotomy was performed permitting the placement of a ventilation tube, but the animals did not require artificial respiration. The left common carotid artery was cannulated to monitor systemic blood pressure and the right jugular vein cannulated for the administration of labeled red blood cells and fluorescently-labeled dextran.

A conventional ventral and postauricular surgical approach was carried out exposing the auditory bulla which was then widely opened, usually with partial removal of the tympanic ring and membrane. The wide opening of the middle ear facilitated the subsequent surgery on the cochlea. These experiments did not require sound stimulation. The tensor tympani tendon was sectioned to eliminate movements which occur as a result of spontaneous contraction of this muscle.

The head was securely fastened in a headholder for positioning under the microscope. The metal headholder was heated to eliminate cooling of the head which could occur independently of the torso (Brown et al., 1983).

Openings to observe the blood circulation in the vessels in the spiral ligament and stria vascularis were made by creating small scratch marks using a knife blade. Generally, this technique resulted in the removal of an intact piece of bone creating a rectangular opening. The dimensions of the opening varied with location. A third turn opening was approximately $0.2 \mathrm{~mm}$ by $0.3 \mathrm{~mm}$ with the long dimension positioned along the direction of the spiral ligament.

Before the cochlear openings were made, a low flow velocity source of $95 \% \mathrm{~N}_{2}, 5 \% \mathrm{CO}_{2}$ gas was directed into the open bulla. The gas was saturated with water vapor at room temperature and heated to ensure that the tissue of the inner ear was exposed to normal concentrations of oxygen and carbon dioxide and was not dried or cooled by the topical application of the gas. The concentration of oxygen and carbon dioxide in the bulla next to the cochlea was monitored by a capillary sampler tube which drew gas at $40 \mathrm{ml} / \mathrm{min}$ through oxygen and carbon dioxide analyzers. The temperature of the cochlea was monitored by a thermocouple placed on the bony surface of the first turn.

Observations of blood flow in the cochlea were accomplished with a custom-designed intravital microscope (Nuttall, 1987). Long-working-distance objective lenses permitted direct observation of capillaries from the video monitor (total system magnification of approximately $1000 \times$ ). Most observations were achieved under fluorescence microscopy conditions. A vertical illumination system provided the excitation light for fluorescence of fluorescein isothiocyanate (FITC) or calcein. Images were received by an image intensified video camera (Dage MTI model 66 silicon intensified target type). They were recorded on video tape (Sony model 5200, 3/4 inch format) for off-line processing.

Velocities of cells flowing in the capillaries of the lateral wall were determined by using the labeled erythrocytes indicator technique. First, $0.05 \mathrm{cc}$ of FITC-dextran (150 kDa mean molecu- 
lar weight) as a $5 \%$ solution by weight in normal saline was given i.v. to achieve a slight fluorescence of the plasma, permitting visualization and recognition of the vessels. Then, approximately 0.2 cc of labeled red blood cells were given i.v. resulting in a small population of fluorescent red cells in the circulation. The cells were labeled according to procedures described by Nuttall (1987). A dual photometric analyzer (IPM model 204) derived signals from the video image which were processed by an electronic timing device for the time delay of the passage of red cells between the known distance of the windows.

Generally, as many vessels as possible which were visible within the surgical opening of the cochlea were examined for the flow velocity of the labeled red blood cells. Measurements reported here are from 8 successful guinea pig experiments.

\section{Results}

Fig. 1 is a schematic drawing of the pattern of blood vessels seen in the lateral wall of the third turn of one guinea pig. The drawing was made from the face of a video monitor and the sizes of the vessels are not to scale. It was possible to measure RBC velocity from most of the visible vessels. In Fig. 1, a pair of numbers appear near the vessels in the drawing indicating where velocity measurements were made. These numbers represent the average velocity of the cells passing that location and the diameter of the vessel [velocity $(\mathrm{mm} / \mathrm{s}) /$ diameter $(\mu \mathrm{m})]$. The letter appearing on certain vessels identifies the location in reference to Table I which gives the flow statistics obtained for a given vessel location.

It is possible to identify the anatomical types of blood vessels in such images by recognizing the pattern of flow (the directions of which are given in Fig. 1 by arrows) and the depth of optical focus where a vessel appears. Thus, as one focuses down through the specimen, the superficial vessels in the spiral ligament are first brought into focus followed by the deeper capillaries within the stria vascularis.

For the purpose of this report, three types of vessels are defined: (1) feeder vessels which divide on the apical side of the stria vascularis into two or more capillaries of the spiral ligament (there are no measured examples of feeder vessels in Fig. 1); (2) arteriovenular (a-v) anastamosing vessels of the spiral ligament which pass directly across the ligament from the scala vestibuli to the scala tympani; and (3) capillaries of the stria vascularis. In Fig. 1 and Table I, the vessels which meet these definitions are labeled with lower case letters for $a-v$ vessels and with capital letters for stria vascularis capillaries.

Table I gives for each vessel, the mean velocity with S.D., the vessel diameter, and the number of red blood cells which were timed. It is clear that the velocities of RBCs in the strial vessels are

TABLE I

THE FLOW STATISTICS OF THE VESSELS SHOWN IN FIG. 1

\begin{tabular}{|c|c|c|c|c|c|c|c|c|}
\hline & \multicolumn{8}{|c|}{ Spiral Ligament Vessels } \\
\hline & $\mathbf{a}$ & b & $\mathrm{c}$ & $\mathrm{d}$ & $\mathrm{e}$ & $\mathrm{f}$ & $\mathrm{g}$ & $\mathrm{h}$ \\
\hline Mean velocity $(\mathrm{mm} / \mathrm{s})$ & 0.18 & 0.12 & 0.10 & 0.12 & 0.18 & 0.09 & 0.12 & 0.11 \\
\hline S.D. & 0.06 & 0.04 & 0.03 & 0.02 & 0.04 & 0.02 & 0.03 & 0.03 \\
\hline Vessel diameter $(\mu \mathrm{m})$ & 12 & 8 & 8.5 & 6.5 & 8 & 13 & 12 & 7 \\
\hline \multirow[t]{3}{*}{ No. of RBCs measured } & 37 & 26 & 22 & 19 & 34 & 15 & 35 & 15 \\
\hline & \multicolumn{8}{|c|}{ Stria Vascularis Vessels } \\
\hline & $\overline{\mathrm{A}}$ & B & $\mathrm{C}$ & D & $E$ & $F$ & $\bar{G}$ & $\mathrm{H}$ \\
\hline Mean velocity $(\mathrm{mm} / \mathrm{s})$ & 0.05 & 0.03 & 0.06 & 0.05 & 0.06 & 0.05 & 0.10 & 0.06 \\
\hline S.D. & 0.04 & 0.01 & 0.03 & 0.03 & 0.01 & 0.04 & 0.05 & 0.04 \\
\hline Vessel diameter $(\mu \mathrm{m})$ & 14.5 & 10.5 & 7.5 & 12 & 11 & 18 & 14.5 & 12 \\
\hline No. of RBCs measured & 14 & 10 & 23 & 12 & 3 & 5 & 15 & 9 \\
\hline
\end{tabular}




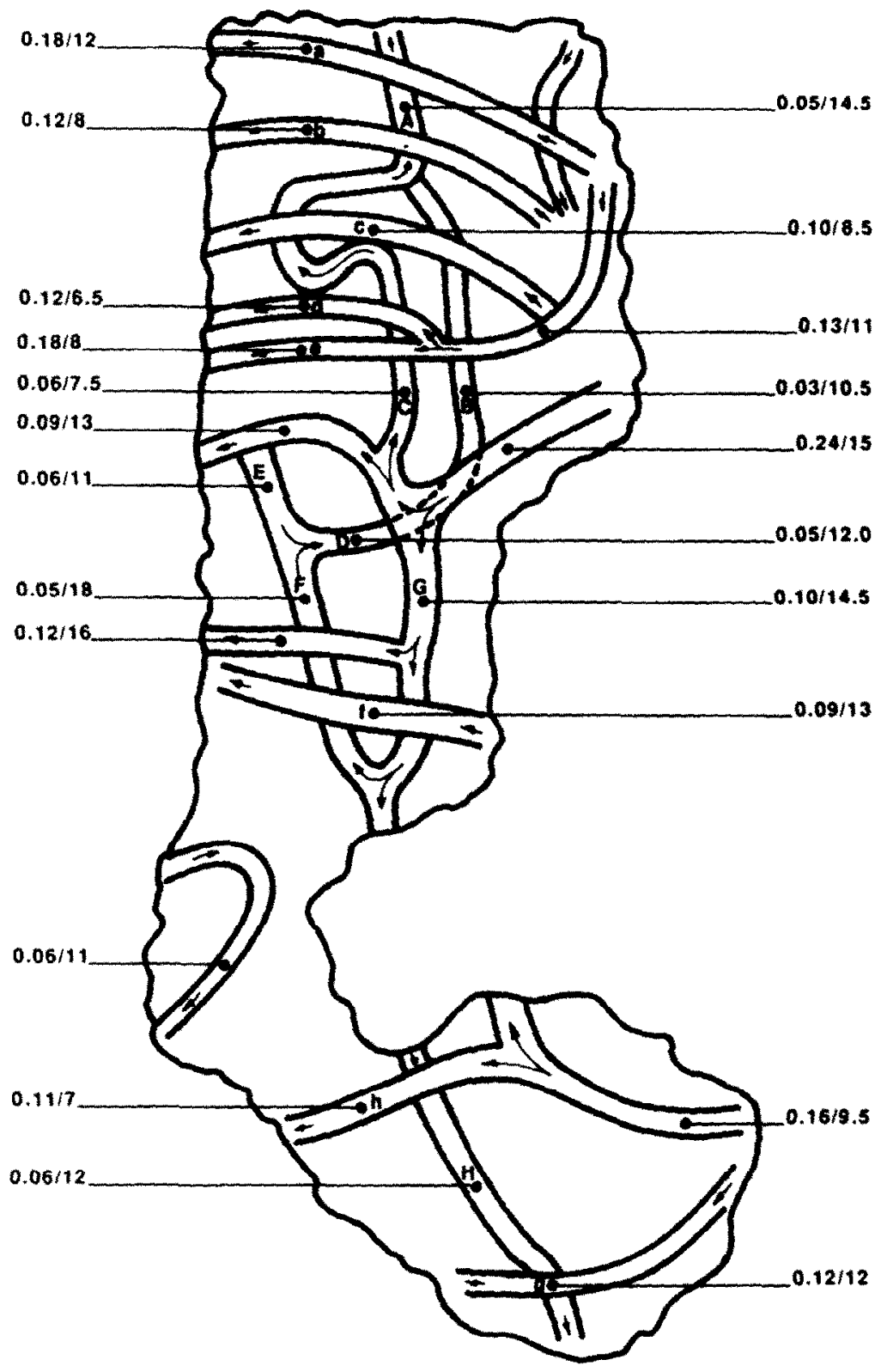

Fig. 1. A schematic drawing of the pattern of capillaries observed in the lateral wall of the third cochlear turn from one guinea pig. Each vessel is labeled at the location where velocity/diameter determinations were made. Lower case letters indicate vessels defined as arteriovenous connecting capillaries in the spiral ligament. Capital letters indicate vessels in the stria vascularis. Arrows give the flow direction of blood. Complete flow statistics from this figure are given in Table 1.

generally much lower (by approximately $1 / 2$ ) than that in capillaries of the spiral ligament and the vessel diameters are larger.

Measurements such as those of Fig. 1 and Table 1 were most successfully accomplished for the third cochlear turn in guinea pigs. Table II summarizes this data for 6 animals. The velocity of blood in the stria vascularis vessels was significantly less than that of the spiral ligament vessels ( $P<0.03$ by one-tailed $t$-statistic). Mean diameter 
TABLE II

THE GROUPED FLOW STATISTICS OF THIRD TURN SPIRAL LIGAMENT AND STRIA VASCULARIS CAPILLARIES IN SIX DIFFERENT GUINEA PIGS

\begin{tabular}{|c|c|c|c|c|c|c|}
\hline Guinea pig no. & 42 & 44 & 45 & 47 & 48 & 50 \\
\hline Blood pressure ( $\mathrm{mmHg}$ ) & 62 & 70 & 51 & 73 & 60 & 60 \\
\hline \multicolumn{7}{|l|}{ Sprial ligament vessels } \\
\hline Mean velocity $(\mathrm{mm} / \mathrm{s})$ & 0.17 & 0.10 & 0.12 & 0.07 & 0.13 & 0.13 \\
\hline S.D. & 0.08 & 0.03 & 0.03 & 0.03 & 0.04 & 0.03 \\
\hline Mean diameter $(\mu \mathrm{m})$ & 8.5 & 10.5 & 9.0 & 10.0 & 8.0 & 9.5 \\
\hline S.D. & 2.0 & 2.0 & 2.0 & 1.5 & 1.5 & 2.5 \\
\hline No. of vessels & 13 & 11 & 8 & 15 & 8 & 8 \\
\hline \multicolumn{7}{|l|}{ Stria vascularis vessels } \\
\hline Mean velocity $(\mathrm{mm} / \mathrm{s})$ & 0.09 & 0.06 & 0.07 & 0.05 & 0.15 & 0.06 \\
\hline S.D. & 0.06 & 0.03 & 0.04 & 0.02 & 0.04 & 0.02 \\
\hline Mean diameter $(\mu \mathrm{m})$ & 12 & 12.5 & 13 & 14 & 9 & 12.5 \\
\hline S.D. & 3.0 & 2.5 & 3.0 & 1.0 & 0.05 & 3.5 \\
\hline No. of vessels & 4 & 9 & 6 & 4 & 2 & 8 \\
\hline
\end{tabular}

of the average strial vessel was larger than vessels of the spiral ligament $(P<0.0001)$.

Comparison of $\mathrm{RBC}$ velocities across cochlear turns is given in Table III. Three guinea pigs were successfully prepared for comparison of the spiral ligament vessels in turns two and three. From the data of Table III, it appears that mean velocity of the flow does not significantly differ between the

TABLE III

THE GROUPED FLOW STATISTICS OF SPIRAL LIGAMENT AND STRIA VASCULARIS CAPILLARIES IN DIFFERENT COCHLEAR TURNS

\begin{tabular}{|c|c|c|c|c|c|}
\hline \multirow{2}{*}{$\begin{array}{l}\text { Cochlear } \\
\text { turn }\end{array}$} & \multirow[b]{2}{*}{ Animal no.: } & \multicolumn{3}{|c|}{ Spiral ligament } & \multirow{2}{*}{$\frac{\text { Stria vascularis }}{50}$} \\
\hline & & 47 & 45 & 50 & \\
\hline 1 & $\begin{array}{l}\text { Mean velocity }(\mathrm{mm} / \mathrm{s}) \\
\text { S.D. } \\
\text { Mean diameter }(\mu \mathrm{m}) \\
\text { S.D. } \\
\text { No. of vessels }\end{array}$ & $\begin{array}{c}0.07 \\
0.03 \\
14 \\
2 \\
10\end{array}$ & & & \\
\hline 2 & $\begin{array}{l}\text { Mean velocity }(\mathrm{mm} / \mathrm{s}) \\
\text { S.D. } \\
\text { Mean diameter }(\mu \mathrm{m}) \\
\text { S.D. } \\
\text { No. of vessels }\end{array}$ & $\begin{array}{l}0.06 \\
0.02 \\
9 \\
1.5 \\
6\end{array}$ & $\begin{array}{l}0.11 \\
0.07 \\
11 \\
1 \\
5\end{array}$ & $\begin{array}{c}0.07 \\
0.03 \\
10.5 \\
1.5 \\
11\end{array}$ & $\begin{array}{l}0.04 \\
0.02 \\
12 \\
0.5 \\
5\end{array}$ \\
\hline 3 & $\begin{array}{l}\text { Mean velocity }(\mathrm{mm} / \mathrm{s}) \\
\text { S.D. } \\
\text { Mean diameter }(\mu \mathrm{m}) \\
\text { S.D. } \\
\text { No. of vessels }\end{array}$ & $\begin{array}{c}0.07 \\
0.03 \\
10 \\
1.5 \\
15\end{array}$ & $\begin{array}{l}0.12 \\
0.03 \\
9 \\
2 \\
8\end{array}$ & $\begin{array}{l}0.13 \\
0.03 \\
9.5 \\
2.5 \\
8\end{array}$ & $\begin{array}{l}0.06 \\
0.02 \\
13 \\
3.5 \\
8\end{array}$ \\
\hline 4 & $\begin{array}{l}\text { Mean velocity }(\mathrm{mm} / \mathrm{s}) \\
\text { S.D. } \\
\text { Mean diameter }(\mu \mathrm{m}) \\
\text { S.D. } \\
\text { No. of vessels }\end{array}$ & $\begin{array}{c}0.07 \\
0.03 \\
13 \\
2 \\
4\end{array}$ & & & \\
\hline
\end{tabular}


second and third turn. In one experimental animal (no. 47), it was possible to make measurements from spiral ligament vessels of all four turns. The distribution of velocities in this animal appears uniform although an apparent difference in vessel size is notable. First and fourth turn capillaries were larger than those of the second and third turns.

In the current study, the greatest velocities that were observed were in feeder vessels. These were vessels which divided into two or more capillaries at the apical border of the observation opening (i.e. at or apical to the location of the vestibular membrane). In the third turn of two guinea pigs (nos. 42 and 48), RBC velocities of 0.27 and 0.28 $\mathrm{mm} / \mathrm{s}$ were observed for two feeder vessels. The spiral ligament capillaries which divided from these feeders had RBC velocities approximately $1 / 2$ the feeder rate.

\section{Discussion}

This study has measured the velocity of red blood cells in capillaries of the guinea pig cochled. In order to accomplish this measurement, two important methodologies were combined; intravital microscopy and fluorescent marker techniques for determining blood flow (see Nuttall, 1987, for a discussion of these methodologies). While intravital microscopy was first applied to observe the living blood vessels of the inner ear more than 30 years ago (Weille et al., 1954; Scymour, 1954) and was shortly thereafter combined with fluorescent techniques (Naumann et al., 1958), it is only recently that appropriate technology has become available to accomplish quantitative measurements with the combined methodology.

The general visual inspection of the capillaries observable through the openings made in the cochlear lateral wall makes it clear that the normal flow is continuous and of constant velocity in all vessels. No capillaries were observed to stop flowing or start spontaneously under the conditions of this study. This impression confirms the same observation by Perlman and Kimura (1955) and Costa and Branemark (1970a,b) but appears to bc in contrast to vessel contractions (with flow alterations) seen by Weille et al. (1954).
In a qualitative sense, the flow velocity of the blood in the lateral wall of the guinea pig cochlea has been described in conflicting terms. Nomura (1961) states that the flow is slow while Costa and Branemark (1970a,b) hold to the opposite view that it is fast. However, all investigators who have distinguished between vessels of the stria and the ligament report a flow difference between stria vascularis and the spiral ligament capillaries; strial vessels being slower (Seymour, 1954; Perlman and Kimura, 1955; Nomura, 1961; Costa and Branemark, 1970a). The current study supports both the view that blood flow in the lateral wall is slow and that strial circulation has the lowest blood velocity.

Mean red cell velocity in all a-v anastamosing vessels of the spiral ligament wcre $0.12 \pm 0.06$ $\mathrm{mm} / \mathrm{s}$. This value appears to be in agreement with Perlman and Kimura (1962). (From their Table I, 6 spiral ligament vessels had an average velocity of $0.218 \mathrm{~mm} / \mathrm{s}$.) It is much lower than the velocity $(0.8 \mathrm{~mm} / \mathrm{s})$ observed by Costa and Branemark (1970b) for $15 \mu \mathrm{m}$ diameter lateral wall capillaries. Similarly, mean strial vessel velocity of $0.08 \pm 0.04$ $\mathrm{mm} / \mathrm{s}$ are close to the Perlman and Kimura (1962) measurement of $0.112 \mathrm{~mm} / \mathrm{s}$ (from 12 strial capillaries in Table $I$ of their paper). No other reports give a quantitative determination of strial flow.

The fastest flow in the vessels of the lateral wall is in the radiating arteriole. Costa and Branemark (1970b) report a velocity greater than $1 \mathrm{~mm} / \mathrm{s}$ while Nomura (1961) measures $0.5 \mathrm{~mm} / \mathrm{s}$ and Perlman and Kimura (1962) give $0.305 \mathrm{~mm} / \mathrm{s}$ (from 6 vessels in their Table I). In the current study, it is not known if the feeder vessels seen branching at the apical edge of the cochlear opening were arterioles as there could have been other branches under the bone out of view. Nevertheless, these feeder vessels had the greatest flow velocity (about $0.27 \mathrm{~mm} / \mathrm{s}$ ), similar again to the Perlman and Kimura (1962) data.

The reason for the discrepancy between the current work (which is in accord with Perlman and Kimura, 1962) and the Costa and Branemark (1970a,b) findings is not apparent. It is probably not related to the measurement technique. In the current work, velocity is estimated by observations of a population of 'indicator cells' which act as 
random samples of the flow over the 2 min video tape period. Costa and Branemark use a 'flying spot' technique (Branemark and Jonsson, 1963) where the investigator matches the speed of a repeating video scan spot to the movement of red cells. The flying spot technique has successfully been used by a number of investigators and satisfactory accuracy has been demonstrated by Tyml and Ellis (1982) for non-cochlear tissues.

The physiological condition of the animal cochlea may be the basis for the difference and no information is provided in the Costa and Branemark papers to evaluate the variables such as blood pressure. It is the current experience of this laboratory that $\mathrm{RBC}$ velocities of the magnitude much greater than $0.2 \mathrm{~mm} / \mathrm{s}$ for spiral ligament vessels can occur under elevated systemic blood pressure conditions (Miles and Nuttall, 1987). However, one would generally expect low blood pressure in the anesthetized guinea pig (Brown et al., 1987).

The velocity of flow in capillaries of noncochlear tissues is generally greater than in spiral ligament vessels and much greater than in stria vascularis vessels. As examples, in rat cremaster muscle flow was found to be $0.7 \mathrm{~mm} / \mathrm{s}$ (Smaje et al., 1970); in rabbit teniussimus muscle, $0.29 \mathrm{~mm} / \mathrm{s}$ (Lindbom et al., 1980); and in cat mesentery, 0.5 $\mathrm{mm} / \mathrm{s}$ (Johnson and Wayland, 1967). So it would seem that cochlear flow is slow. However, currently not much can be said about the significance of this finding nor about the difference between the flow velocity in the spiral ligament verses the stria vascularis. Low velocity could result from either a low differential perfusion pressure across the lateral wall or a high flow resistance of cochlear vessels or a combination of both factors.

From a functional viewpoint, what is important is the microvascular transit time (the product of flow velocity and the capillary path length). A red cell must stay in a capillary long enough to release chemically bound oxygen. The kinetics of the exchange is in the order of tenths of a second (Wagner, 1977) and thus for most tissues capillary path lengths are in excess of the minimum required for complete gas exchange (Sarelius et al., 1981). Furthermore, recruitment of capillaries (from branching and sphincter control) can, in some tissues, effectively alter the 'functional path length' (Sarelius et al., 1981; Sarelius, 1986).

It is obvious that the reduced flow velocity of blood in strial vessels is a direct result of their increased size (by Bernoulli's principle) but currently, since no information is available about pathlength, one cannot tell if this results in a longer transit time. It is possible that the path length through the stria is short and a compensatory slowing of velocity is required for efficient gas exchange. However, in a vascular network with the complexity of the membranous cochlear lateral wall, the question will require further investigation.

A second finding of the current study is the size difference between spiral ligament and strial capillaries. This is a statistically significant result. The absolute size of a capillary, however, is subject to certain measurement error and care must be taken in the interpretation of these data. The error is due primarily to the visual misjudgment of a vessel size on a television monitor. The distribution of intensity across the lumen of a capillary is not constant, rather it falls to zero gradually toward both edges of the vessel. Thus, size judgments are affected by the contrast and brightness settings of the television monitor. Miles and Nuttall (1987) estimate that such visual size judgments are as much as $20 \%$ smaller than the actual vessel size (assuming typical brightness settings of the monitor). This means that in vivo capillary diameters may be greater than those reported for fixed cochlear tissues (Axelsson, 1968). Actual vessel in vivo diameters can be determined from mathematical criteria describing the fluorescence intensity profile across a capillary (Miles and Nuttall, 1987).

\section{Acknowledgments}

This work was supported by Public Health Service NIH program project (NS-05785) and NIH individual grant (NS-11731). Fentanyl citrate, for animal anesthesia, was a gift from the Jannsen Pharmaceutical Company. The author wishes to express his gratitude to J. Nadine Brown and Michelle Griffiths for the technical support and Robert I. Masta for the engineering support of this study. 


\section{References}

Axelsson, A. (1968) The vascular anatomy of the cochlea in the guinea pig and in man. Acta Oto-Laryngol. Suppl. 243, 1-134.

Branemark, P.I. and Jonsson, I. (1963) Determination of the velocity of corpuscles in blood capillaries. A flying spot device. Biorheology 1, 143-146.

Brown, J.N., Thorne, P.R. and Nuttall, A.L. (1987) Blood pressure in the awake and anesthetized guinea pig. In preparation.

Brown, M.C., Smith, D.I. and Nuttall, A.L. (1983) The temperature dependency of neural and hair cell responses evoked by high frequencies. J. Acoust. Soc. Am. 73, 1662-1670.

Costa, O. and Branemark, P.I. (1970a) Microvascular physiology of the cochlea. Adv. Microcirc. 3, 108-114.

Costa, O. and Branemark, P.I. (1970b) Vital microscopic evaluation of the microvessels of the cochlea. Adv. Microcirc. 3, 96-107.

Johnson, P.C. and Wayland, H. (1967) Regulation of blood flow in single capillaries. Am. J. Physiol. 212, 1405-1415.

Lindbom, L., Tuma, R.F. and Arfors, K.-E. (1980) Influence of oxygen on perfused capillary density and capillary red cell velocity in rabbit skeletal muscle. Microvasc. Res. 19, 197-208.

Miles, F. and Nuttall, A.L. (1987) Quantitative in vivo measurement of blood vessel diameters in the lateral wall of the cochlea. Abstr. Tenth Midwinter Res. Meet. Assoc. Res. Otolaryngol., February, Clearwater Beach, FL, pp. 27-28.

Naumann, H.-H., Günther, H. and Schicker, S. (1958) Intravital-Beobachtungen an den Gefaßßen des Innenohres. Arch. Ohren-Nasen Kehlkopfheilkd. 171, 354-366.

Nomura, Y. (1961) Observations on the microcirculation of the cochlea. Ann. Otol. 70, 1037-1054.
Nuttall, A.L. (1987) Techniques for the observation and measurement of red blood velocity in vessels of the guinea pigs cochlea. Hear. Res. 27, 000-000.

Perlman, H.B. and Kimura, R.S. (1955) Observations of the living blood vessels of the cochlea. Ann. Otol. 64, 1176-1192.

Perlman, H.B. and Kimura, R.S. (1962) Cochlear blood flow in acoustic trauma. Acta Oto-Laryngol. 54, 99-110.

Sarelius, I.H. (1986) Cell flow path influences transit time through striated muscle capillaries. Am. J. Physiol. 250, H899-H907.

Sarelius, I.H., Damon, D.N. and Duling, B.R. (1981) Microvascular adaptations during maturation of striated muscle. Am. J. Physiol. 241, H317-H324.

Seymour, J.C. (1954) Observations on the circulation in the cochlea. J. Laryngol. Otol. 68, 689-711.

Smaje, L., Zweifach, B.W. and Intaglietta, M. (1970) Micropressures and capillary filtration coefficients in single vessels of the cremaster muscle of the rat. Microvasc. Res. 2 , 96-110.

Smith, C.A. (1951) Capillary areas of the cochlea in the guinea pig. Laryngoscope 61, 1073-1095.

Smith, C.A. (1954) Capillary areas of the membranous labyrinth. Ann. Otol. Rhinol. Laryngol. 63, 435-447.

Tyml, K. and Ellis, C.G. (1982) Evaluation of the flying spot technique as a television method for measuring red cell velocity in microvessels. Int. J. Microcirc. Clin. Exp. 1. $145-155$.

Wagner, P.D. (1977) Diffusion and chemical reaction in pulmonary gas exchange. Physiol. Rev. 57, 257-312.

Weille, F.L., Gargano, S.R., Pfister, R., Martinez, D. and Irwin, J.W. (1954) Circulation of the spiral ligament and stria vascularis of living guinea pig. Arch. Otolaryngol. 59, 731-738. 